\title{
Amphetamine Exposure Enhances Accumbal Responses to Reward-Predictive Stimuli in a Pavlovian Conditioned Approach Task
}

\author{
Xun Wan ${ }^{1}$ and Laura L. Peoples ${ }^{2,3}$ \\ ${ }^{1}$ Department of Psychology, University of Pennsylvania, ${ }^{2}$ Department of Psychiatry, and ${ }^{3}$ Neuroscience Graduate Group, University of Pennsylvania School \\ of Medicine, Philadelphia, Pennsylvania 19104
}

Acute and repeated exposure to psychostimulants such as amphetamine enhances the effects of pavlovian conditioned stimuli on conditioned behavior. It is hypothesized that amphetamine facilitates conditioned stimulus (CS) effects by selectively enhancing accumbal neuronal responses to stimuli. To test this hypothesis, rats were trained to discriminate between two pavlovian stimuli. One stimulus (i.e., CS+) was paired with sucrose delivery [i.e., unconditioned stimulus (US)], and the other stimulus (i.e., CS -) was paired with the absence of sucrose. Animals developed a conditioned approach response that occurred during the CS + but not during the CS-. We tested the effect of different doses of amphetamine $(0,0.25,0.5$, or $1.0 \mathrm{mg} / \mathrm{kg})$ on this conditioned approach behavior as well as on accumbal neuronal responses time locked to the CS + , the $\mathrm{CS}-$, and the US. Acute amphetamine exposure increased conditioned approach behavior during the $\mathrm{CS}+$, but not during the $\mathrm{CS}-$. This change in behavior was associated with a selective increase in the magnitude of accumbal responses during the $\mathrm{CS}+$. Repeated amphetamine administration followed by a drug-free period and reexposure did not affect the conditioned behavior, but increased accumbal responses to the CS + . These findings support the hypothesis that amphetamine exposure enhances behavioral responses to pavlovian conditioned stimuli by amplifying accumbal responses to those stimuli.

Key words: psychostimulant; dopamine; electrophysiology; addiction; learning; sensitization

\section{Introduction}

Positive pavlovian conditioned stimuli are predictive of particular rewards (i.e., biologically significant events such as food access). These pavlovian conditioned stimuli can direct, energize, and reinforce behaviors that lead animals to contact reward. Specifically, presentations of a positive pavlovian conditioned stimulus (i.e., CS+) will evoke (i.e., direct) approach either toward the stimulus or toward the anticipated location of the reward. Presentations of a CS + when animals are engaged in behavior that has previously led to reward can increase (i.e., energize) the vigor with which animals execute the behavior. Finally, CS + presentations that are contingent on a new behavioral response can facilitate (i.e., reinforce) the acquisition of the new behavior. Pavlovian conditioned stimulus effects on behavior are implicated in the regulation of normal behavior and may be relevant to certain neuropsychiatric disorders (Everitt et al., 2001; Winstanley et al.,

\footnotetext{
Received March 11, 2008; revised May 20, 2008; accepted June 4, 2008.

This work was supported by National Institutes of Health (NIH)/National Institute on Drug Abuse (NIDA) Grant P60 DA-05186 to C. P. O'Brien and by NIH/NIDA Grant P50 DA 012756 to H. Pettinati. We thank Alexxai Kravitz for his helpful comments on this manuscript.

Correspondence should be addressed to Dr. Laura L. Peoples, Department of Psychiatry, University of Pennsylvania School of Medicine, TRL Building, 125 South 31st Street, Philadelphia, PA 19104. E-mail: Ipeoples@mail.med.upenn.edu.

DOI:10.1523/JNEUROSCI.1071-08.2008

Copyright $\odot 2008$ Society for Neuroscience $\quad 0270-6474 / 08 / 287501-12 \$ 15.00 / 0$
}

2006; Day and Carelli, 2007). Therefore, it is of interest to identify mechanisms that underlie and modulate pavlovian conditioning.

Multiple lines of animal research show that acute exposure to amphetamine (AMPH) can enhance the energizing and reinforcing effects of CS + stimuli (Robbins, 1978; Wyvell and Berridge, 2000). A history of repeated exposure to AMPH, particularly if followed by an extended drug-free period, can also amplify the effects of CS + stimuli (Harmer and Phillips, 1998; Taylor and Jentsch, 2001; Wyvell and Berridge, 2001). Converging evidence indicates that these drug effects are mediated in part by AMPHinduced changes in dopaminergic (DA) actions in the nucleus accumbens (NAc). Therefore, it is hypothesized that these actions of AMPH facilitate conditioned behavior by enhancing NAc neuronal responses to CS+ stimuli. However, the effects of acute and repeated AMPH on NAc responses to CS+ stimuli are not yet known.

Given these observations, the present study investigated the effects of acute and repeated AMPH on NAc responses to CS+ stimuli. Long-Evans rats were exposed to pavlovian conditioning sessions. During the sessions, two sensory stimuli were presented to animals in a programmed order. One stimulus (i.e., $\mathrm{CS}+$ ) was consistently paired with delivery of sucrose [i.e., unconditioned stimulus (US)] to a trough, whereas the other stimulus (i.e., negative conditioned stimulus, $\mathrm{CS}-$ ) was paired with the absence of sucrose. Across conditioning sessions, the frequency with which animals approached the sucrose trough increased during presen- 
tations of the CS+ but not during presentations of the CS-. After the initial conditioning phase, we used chronic extracellular recording procedures to characterize the effect of presession injections of saline and several different doses of AMPH (i.e., acute AMPH) on NAc neuronal responses to the $\mathrm{CS}+$, the $\mathrm{CS}-$, and the US. After a subsequent 2- to 4-week drugfree period, the effect of presession saline and AMPH administration was evaluated for a second time. The AMPH effects during the first and second set of AMPH sessions were compared to determine the effects of repeated AMPH. The experiments show that both acute and repeated AMPH selectively enhance NAc responses to CS+ stimuli. The findings provide novel information regarding mechanisms that influence pavlovian conditioned stimulus effects on behavior.

\section{Materials and Methods Subjects}

Subjects were 10 male Long-Evans rats (Charles River). Animals were individually housed on a reverse $12 \mathrm{~h}$ light-dark cycle in a ventilated environment and had ad libitum access to water except during the daily experimental sessions. One week after surgery, food restriction was imposed to maintain the subjects' body weight at $\sim 375$ g. All animal care and protocols were in accordance with the Guide for the Care and Use of Laboratory Animals published by the United States Public Health Service and approved by the Animal Care and Use Committee of the University of Pennsylvania.

\section{Surgery}

Rats were initially anesthetized with a mixture of ketamine $(100 \mathrm{mg} / \mathrm{kg}$, i.p.) and xylazine (10 $\mathrm{mg} / \mathrm{kg}$, i.p.). Anesthesia was maintained with isoflurane through a nose cone during surgery. One recording array (MicroProbe) was implanted unilaterally into the NAc [anteroposterior, +0.5 to $+3.0 \mathrm{~mm}$ from bregma; mediolateral, \pm 0.5 to \pm 1.5 from the midline; dorsoventral, +6.8 from the skull (Paxinos and Watson, 2005)]. The array was rectangular in configuration and consisted of two rows of 8 quad-Teflon-coated stainless-steel microwires. The two rows were separated by a space of 0.5 $\mathrm{mm}$. Each row was $2 \mathrm{~mm}$ in length. The diameter of each wire was $40 \mu \mathrm{m}$, and adjacent wires within each row were $\sim 0.25 \mathrm{~mm}$ apart (wire center to wire center). A separate ground wire was implanted $4 \mathrm{~mm}$ into the ipsilateral side of the brain, $5 \mathrm{~mm}$ caudal to bregma. The headstage of the array was fixed to the skull with acrylic dental cement and secured with stainless-steel bone screws. A more detailed description of the surgical procedures was provided in another report (Peoples, 2003).

\section{Apparatus}

All training and electrophysiological recording sessions were conducted in Plexiglas experimental chambers $(30 \times 35 \times 30 \mathrm{~cm}$, length $\times$ width $\times$ height) purchased from Med Associates. The chambers were enclosed in sound-attenuating and ventilated cubicles. Each chamber contained a food trough built into one wall. A small well at the base of the trough was used as the delivery site for sucrose. The well was equipped with a customized lickometer and attached via tubing to a motorized syringe pump located outside the cubicle. A red house light $(2.5 \mathrm{~cm}$ in diameter), a white stimulus light $(2.5 \mathrm{~cm}$ in diameter $)$ and a speaker were fixed on the ceiling of the cubicle. The food trough was equipped with photobeam devices, which were used to detect when the animal's head entered and exited the food trough. Experimental events were controlled and recorded using customized programs. All experimental sessions were videotaped.

\section{Behavioral procedures \\ Overview}

Rats underwent four major phases of training and testing (Fig. $1 \mathrm{~A}$ ). First, during preliminary training, animals were habituated to the experimental chamber for $1 \mathrm{~d}$. This session was followed on the next day by a single magazine training session, during which animals were conditioned to associate the food trough with sucrose delivery. Second, animals were exposed to daily pavlovian conditioning sessions, during which they were trained to associate one stimulus with delivery of sucrose and a second stimulus with the absence of sucrose (i.e., pavlovian conditioning phase). The effects of acute AMPH on NAc neuronal activity were characterized in a third (i.e., acute AMPH) phase. All animals were exposed to five additional pavlovian conditioning sessions. Each of the sessions was preceded by a presession injection of AMPH, the dose of which varied across sessions. In the final (i.e., repeated AMPH) phase of the study, a subset of the animals were exposed to a drug-free and training-free period and then reexposed to two additional conditioning sessions, during which we recorded the effects of acute AMPH on neuronal activity.

\section{Preliminary training}

On the first day of training, animals were habituated to the experimental chamber. Subjects were placed in the chamber for a $2 \mathrm{~h}$ period, during 


\begin{tabular}{|c|c|c|}
\hline Session & $n$ & Firing rate $(\mathrm{Hz})$ \\
\hline \multicolumn{3}{|l|}{ Acute AMPH } \\
\hline $0 \mathrm{mg} / \mathrm{kg}$ AMPH & 123 & $2.72 \pm 0.25$ \\
\hline $0.25 \mathrm{mg} / \mathrm{kg}$ AMPH & 114 & $2.70 \pm 0.26$ \\
\hline $0.5 \mathrm{mg} / \mathrm{kg}$ AMPH & 127 & $2.62 \pm 0.30$ \\
\hline $1.0 \mathrm{mg} / \mathrm{kg} \mathrm{AMPH}$ & 117 & $2.85 \pm 0.32$ \\
\hline \multicolumn{3}{|l|}{ Repeated AMPH } \\
\hline $0 \mathrm{mg} / \mathrm{kg}$ AMPH before & 68 & $2.90 \pm 0.41$ \\
\hline $0.25 \mathrm{mg} / \mathrm{kg}$ AMPH before & 61 & $2.85 \pm 0.42$ \\
\hline $0 \mathrm{mg} / \mathrm{kg}$ AMPH after & 70 & $3.25 \pm 0.40$ \\
\hline $0.25 \mathrm{mg} / \mathrm{kg}$ AMPH after & 57 & $3.03 \pm 0.43$ \\
\hline
\end{tabular}

Presession baseline firing rates across different sessions were not significantly different during either the acute AMPH phase (1-way ANOVA, $p>0.05$ ) or the repeated AMPH test (2-way ANOVA, $p>0.05$ ). In the repeated AMPH test, "before" indicates sessions before the drug-free periods, and "after" indicates sessions after the drug-free period.

which the red house light was illuminated. Animals were exposed to no other stimuli during the habituation session. On the subsequent day, animals were exposed to a magazine training session. The magazine training session began with illumination of the red house light. During the session, $0.2 \mathrm{ml}$ of a $10 \%$ sucrose solution was delivered 30 times on a variable interval (VI) $60 \mathrm{~s}$ schedule. The magazine training session was bracketed by a $1 \mathrm{~h}$ presession period and a $30 \mathrm{~min}$ postsession period, during which the animal remained in the chamber. During these periods the chamber was dark.

\section{Pavlovian conditioning}

After magazine training, 10 daily sessions of pavlovian conditioning were conducted. Similar to the magazine training session, each pavlovian conditioning session was bracketed by a $1 \mathrm{~h}$ presession period and a $30 \mathrm{~min}$ postsession period. During each daily session, two distinctive sensory stimuli were presented on a VI 1.5 min schedule. One stimulus (i.e., positive conditioned stimulus, $\mathrm{CS}+$ ) was always paired with the delivery of sucrose $(0.2 \mathrm{ml}$ of $10 \%$ sucrose solution delivered in $5 \mathrm{~s})$ to the food trough, whereas the other stimulus was consistently paired with the absence of sucrose (i.e., negative conditioned stimulus, CS - ). There were 20 presentations of each stimulus. The stimuli were presented in a random order with the restriction that no more than two presentations (i.e., trials) of the same stimulus occurred consecutively. For half of the subjects, the CS+ was a $10 \mathrm{~s}$ illumination of the white ceiling light and the $\mathrm{CS}-$ was a $10 \mathrm{~s}$ white noise emitted from the ceiling speaker. For the remaining subjects, the assignment of CS + and CS - was reversed. During the session, the time of each trough head entry and exit was recorded by the photobeam devices. Each tongue intrusion into the sucrose well was recorded by the lickometer.

\section{Acute AMPH}

Habituation to the injection procedure. At the start of the acute AMPH phase, animals were habituated to receiving intraperitoneal injections. The habituation procedure involved exposing animals to presession injections of saline on each of three days of conditioning. The injection (1.0 $\mathrm{ml} / \mathrm{kg}$ saline, i.p.) was administered at the end of the presession period and $10 \mathrm{~min}$ before the onset of the pavlovian conditioning session (Fig. $1 B)$.

Baseline recording session. After the $3 \mathrm{~d}$ of injection habituation, a baseline electrophysiological recording session was conducted. The procedure of the baseline recording session was identical to the three preceding saline-injection sessions (Fig. $1 B$ ). An acute AMPH dose-response curve was determined after the baseline recording session.

Acute AMPH sessions. Testing sessions were conducted every other day during determination of an AMPH dose-response curve. The sessions were identical to the baseline recording session except that an AMPH injection was substituted for a saline injection (Fig. $1 B$ ). Four doses of AMPH $(0,0.25,0.5$, and $1.0 \mathrm{mg} / \mathrm{kg}$, dissolved in sterile saline) were administered to each subject (i.e., volume $1.0 \mathrm{ml} / \mathrm{kg}$ ), one dose per session. The doses of AMPH were administered according to a Latin Square design, in which the dose sequence varied across subjects but was coun- terbalanced across the whole population of subjects. The procedure dissociated dose and days of cumulative drug exposure and thus controlled for possible effects of cumulative drug exposure on behavior and neuronal activity.

\section{Repeated AMPH}

After the last session of acute AMPH administration, five subjects were exposed to a 2-4 week drug- and training-free period (referred to henceforth as the drug-free period). Then, the subjects underwent two pavlovian conditioning sessions (separated by $2 \mathrm{~d}$ ). Animals were administered 0 and $0.25 \mathrm{mg} / \mathrm{kg}$ AMPH (volume $1.0 \mathrm{ml} / \mathrm{kg}$ ) before the start of the first and second session, respectively.

\section{Electrophysiological recordings}

Electrophysiological recordings were conducted on preselected days, including several days during the initial pavlovian conditioning phase (not described herein), the acute AMPH phase, and the final repeated AMPH phase. On electrophysiological recording days, the electrode headstage on the animal was attached via a flexible recording cable to an electronic swivel. The swivel was attached to filtering and amplification equipment outside the sound-attenuating cubicle. Neuronal signals were led to a computer running the Multichannel Acquisition Processor software (MAP; Plexon). On-line isolation of recorded waveforms was accomplished using the MAP system. All waveforms that exceeded an amplitude threshold were time stamped ( $1 \mu$ s resolution) and saved for subsequent off-line analysis. Occurrence of experimenter-determined events (e.g., CS+) was time stamped according to the same computer clock that was used to time stamp waveforms.

After the recording session, Off-Line Sorter (Plexon) was used to further discriminate neural waveforms. Briefly, all recorded waveforms were plotted in several two- and three-dimensional scatter plots. Waveforms that shared similar principle component values formed distinct clusters and were defined as units. Units that met an interspike interval criterion $(<3 \%$ of interspike intervals were $<1900 \mu \mathrm{s})$ and a signal-tonoise criterion $(\geq 2.5 \times$ noise band in amplitude) were defined as single neurons and included in analysis. Units that did not meet either the interspike interval criterion or the amplitude criterion were excluded from the study.

\section{Data analysis}

\section{Behavior}

In the present study, head entry into the food trough (i.e., trough entry) was used as the dependent measure of conditioned approach behavior. For each recording session, the number of trough entries was counted during each of three intervals: the $10 \mathrm{~s}$ CS + period, the $10 \mathrm{~s} C S-$ period, and the $5 \mathrm{~s}$ US period. The total number of trough entries during each interval was converted to a frequency measure for further comparisons (i.e., frequency of trough entries $=$ number of trough entries/duration of the interval).

The repeated AMPH regimens that have been observed in previous studies to enhance the energizing and conditioned reinforcing effects of conditioned stimuli are consistent with those that can induce sensitization to the locomotor-activating effects of AMPH (Robinson and Becker, 1986). For the purposes of between-experiment comparisons, it was thus of interest to test whether the AMPH regimen used in the present study was sufficient to induce locomotor sensitization. To test for sensitization to the locomotor-activating effects of AMPH in the present study, locomotion was quantified by video analysis during the 0 and $0.25 \mathrm{mg} / \mathrm{kg}$ AMPH sessions before and after the drug-free period (i.e., total of four sessions). Within each session, locomotor behaviors were scored during the $10 \mathrm{~s}$ pre-CS + and CS+ periods. The total distance traveled was then calculated for each of those periods. Specifically, we identified locomotion from one side of a chamber wall to the other, from one side of the chamber to the other, and from one diagonal corner to the other. The number of occurrences of these movements was then converted into the total number of centimeters traversed. The measure was then subjected to a repeated-measures ANOVA to test for an increase in locomotion across sessions. 


\section{Firing patterns}

Normalization of firing rate data. To minimize variability in firing rates across individual neurons, the raw firing rate of each neuron was normalized to a presession firing rate (i.e., presession firing rate $=$ total number of discharges during the $1 \mathrm{~h}$ presession period/3600 s). Table 1 summarizes average presession firing rate during all of the recording sessions. ANOVAs $(\alpha=0.05)$ showed that average presession firing rate was stable across the sessions. An additional analysis that segregated neurons into subgroups based on their time-locked responses to the CS+, the CS-, and the US also indicated that there was no change in the presession firing rate across the subgroups (data not shown). Therefore, between-session comparisons of normalized firing rate were not biased by potential changes in the presession firing rate.

Firing patterns time locked to session events. Each neuron was tested for time-locked responses to the CS+, the CS-, and the US. Responses to the CS+ were examined on two time bases: (1) the $20 \mathrm{~s}$ interval between -10 s pre-CS+ and the offset of the $10 \mathrm{~s}$ CS+ stimulus; and (2) the $4 \mathrm{~s}$ period between $-2 \mathrm{~s}$ pre-CS + and $+2 \mathrm{~s}$ after CS + onset. For the long time-base analysis, the normalized firing rate during the $10 \mathrm{~s}$ CS + was compared with that during the $10 \mathrm{~s}$ pre-CS + . To conduct the test, firing rate during the $10 \mathrm{~s}$ pre-CS + and the $10 \mathrm{~s}$ CS + was calculated on a bin-by-bin basis (bin width of $250 \mathrm{~ms}$ ). The pre-CS+ and CS + firing rates were then compared in a Wilcoxon test ( $\alpha=0.01$; SPSS). If a neuron exhibited a significant change in firing (positive or negative), it was classified as exhibiting a "long-lasting" CS + response. If a neuron lacked a long-lasting CS + response, a similar comparison was made between the first $2 \mathrm{~s}$ of the CS+ and the $2 \mathrm{~s}$ pre-CS+ (i.e., based on the short time-base). If a significant change in firing was found, the neuron was classified as having a transient CS+ response. If a neuron did not exhibit either a long-lasting or a transient response to the $\mathrm{CS}+$, it was defined as nonresponsive to the CS+. Identical procedures were used to test for changes in firing time locked to the CS -. Time-locked responses to the US were examined by comparing the normalized firing rate during the first $10 \mathrm{~s}$ of US consumption (i.e., referred to as the US) to that during the $10 \mathrm{~s}$ pre-CS+.

Effect of acute AMPH on firing patterns time locked to the CS+, the CS-, and the US. We tested for an effect of acute AMPH on CS +, CS-, and US responses. To test for an acute AMPH effect on CS+ responses, the average normalized firing rate of neurons responsive to the CS+ (i.e., $\mathrm{CS}+$ neurons) was determined for the $\mathrm{CS}+$ and the $\mathrm{CS}-$ at each AMPH dose. The average firing rates were then compared using an ANOVA $(\alpha=0.05)$. Comparable procedures were used to test for an acute AMPH effect on CS - responses. To test for an AMPH effect on US firing, the average normalized firing rate of neurons responsive to the US (i.e., US neurons) was determined for the $10 \mathrm{~s}$ US period and the $10 \mathrm{~s}$ pre-CS + at each AMPH dose. The firing rates were then compared using an ANOVA.

Effect of repeated AMPH on firing patterns time locked to the CS+, the $\mathrm{CS}-$, and the US. To test for an effect of repeated AMPH on CS+, CS-, and US responses, average firing rates were calculated during the event period and a comparison period, as described above. Average firing rates were compared across the following four sessions: (1) the 0 and 0.25 $\mathrm{mg} / \mathrm{kg}$ AMPH sessions before the drug-free period, and (2) the 0 and 0.25
B
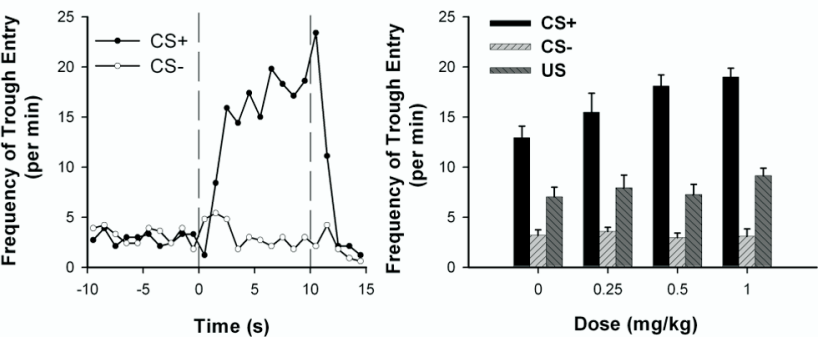

Figure 2. Frequency of trough entry during the acute AMPH phase. $A$, For the baseline session, the average frequency of Table 2. Prevalence of $\mathrm{CS}+, \mathrm{CS}-$, and US NAc responses during the acute AMPH phase, segregated by response

\begin{tabular}{ccccc} 
Baseline & $0 \mathrm{mg} / \mathrm{kg}$ & $0.25 \mathrm{mg} / \mathrm{kg}$ & $0.5 \mathrm{mg} / \mathrm{kg}$ & $1 \mathrm{mg} / \mathrm{kg}$ \\
\hline $22(19 \%)$ & $28(23 \%)$ & $27(24 \%)$ & $21(17 \%)$ & $25(21 \%)$ \\
$8(7 \%)$ & $7(6 \%)$ & $5(4 \%)$ & $8(6 \%)$ & $5(4 \%)$ \\
& & & & \\
$32(28 \%)$ & $40(33 \%)$ & $32(28 \%)$ & $39(31 \%)$ & $32(27 \%)$ \\
$4(3 \%)$ & $4(3 \%)$ & $2(2 \%)$ & $2(2 \%)$ & $4(3 \%)$ \\
& & & & \\
$11(10 \%)$ & $18(16 \%)$ & $15(13 \%)$ & $12(9 \%)$ & $14(12 \%)$ \\
$4(3 \%)$ & $5(4 \%)$ & $5(4 \%)$ & $6(5 \%)$ & $7(6 \%)$ \\
$5(4 \%)$ & $7(6 \%)$ & $4(4 \%)$ & $5(4 \%)$ & $3(3 \%)$ \\
$2(2 \%)$ & $1(1 \%)$ & $2(2 \%)$ & $2(2 \%)$ & $3(3 \%)$ \\
$31(27 \%)$ & $37(30 \%)$ & $35(31 \%)$ & $33(26 \%)$ & $33(28 \%)$ \\
$37(32 \%)$ & $40(33 \%)$ & $37(32 \%)$ & $42(33 \%)$ & $40(34 \%)$ \\
115 & 123 & 114 & 127 & 117 \\
\hline
\end{tabular}

$\mathrm{mg} / \mathrm{kg}$ sessions after the drug-free period. Firing rates were compared using ANOVAs $(\alpha=0.05)$.

Behavioral clamp control analysis. For some neurons, firing rate was calculated during periods in which the animal was engaged in particular behaviors. Specifically, we focused on three behavioral periods during the $10 \mathrm{~s}$ CS+ presentation: an "in" period in which the subject was engaged in trough entry, an "exit" period in which the subject was withdrawing from trough entry, and an "out" period in which the subject remained out of the trough and was engaged in behaviors other than trough entry. Operationally, the "in" period was defined as the $500 \mathrm{~ms}$ immediately after a trough entry. The "exit" period equaled the $500 \mathrm{~ms}$ immediately after a head exit from the trough. The "out" period was the $500 \mathrm{~ms}$ immediately after the median point of an interval in which the subject remained out of the trough for $>1 \mathrm{~s}$. ANOVAs were used to compare average firing rates during the different periods.

\section{Histology}

Rats were injected with a lethal dose of ketamine after the last recording session. Anodal current ( $50 \mu \mathrm{A}$ for $4 \mathrm{~s}$ ) was passed through each microwire. The animals were then perfused with $4 \%$ paraformaldehyde. Coronal sections $(30 \mu \mathrm{m})$ were mounted on slides and incubated in a solution of $5 \%$ potassium ferricyanide and $10 \% \mathrm{HCl}$ to stain the ion deposits left by the recording tip. The tissue was counterstained with $0.2 \%$ solution of Neutral Red. The location of each wire tip was plotted on the coronal plate (Paxinos and Watson, 2005) that most closely corresponded to its antero-posterior position. Recorded neurons were then classified as core, shell, or border neurons based on Paxinos and Watson (2005). In 
A

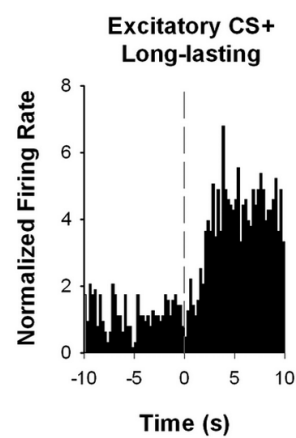

B

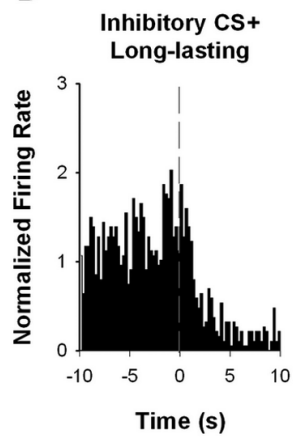

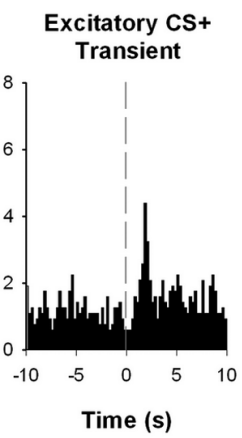
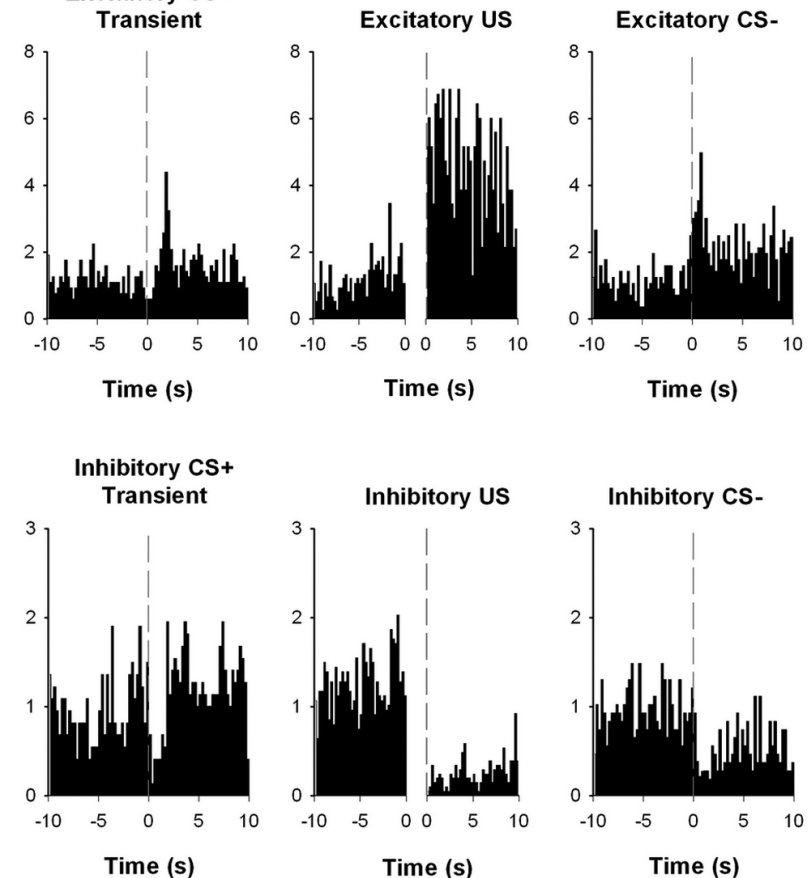

particular, lesion centers within $150 \mu \mathrm{m}$ of the core-shell border were defined as border neurons. Neurons recorded from extra-accumbal structures were excluded from analyses.

\section{Results}

Histology

Neuronal activity was recorded from 144 wires located within the NAc. Of the 144 wires, $61(42 \%)$ were in the core and 34 $(24 \%)$ were in the shell (Fig. $1 C$ ). The remaining wires were along the core-shell border.

\section{Baseline recording session \\ Behavior}

During the baseline recording session, rats demonstrated behavioral discrimination between the CS+ and the CS- (Fig. 2A). A paired $t$ test showed that the frequency of trough entry during the CS + was significantly higher than that during the CS$\left(t_{(9)}=7.103 ; p<0.001\right)$. A more detailed characterization of trough entry during the CS+ (Fig. 2B) showed that the frequency of trough entry increased gradually across the $10 \mathrm{~s}$ CS + , peaking shortly after the offset of the CS + . Thereafter, the frequency of trough entry decreased and remained low during the US.

\section{Firing patterns}

During the baseline recording session, $83 \%$ of recorded neurons responded to at least one event. Among the responsive neurons, $72 \%$ showed a change in firing during the US, $69 \%$ showed a change in firing during the CS+, and $23 \%$ showed a change in firing during the CS-. A small set of stimulus responses were transient. However, the majority of CS + and CSresponses were sustained across the entire $10 \mathrm{~s}$ stimulus presentation. Therefore, all analyses focused on the long-lasting firing patterns. The prevalence of each type of firing pattern is presented in Table 2. Individual neuron examples are presented in Figure 3. The firing patterns observed during the baseline session were consistent with those observed in a previous study (Wan and Peoples, 2006).

\section{Acute AMPH}

\section{Behavior}

Acute AMPH selectively increased the frequency of trough entry during the CS+ relative to the $\mathrm{CS}-$ (Fig. $2 \mathrm{C}$ ). A two-way repeated-measures ANOVA with dose (i.e., $0,0.25,0.50$, and $1.0 \mathrm{mg} / \mathrm{kg}$ ) and stimulus (i.e., $\mathrm{CS}+$ and $\mathrm{CS}-$ ) as factors showed that there was a significant dose $X$ stimulus interaction $\left(F_{(3,27)}=7.832 ; p<\right.$ $0.001)$ and a significant effect of dose $\left(F_{(3,27)}=4.274 ; p<0.05\right)$. AMPH did not 
affect the frequency of trough entry during the US $\left(F_{(3,27)}=2.281 ; p=0.102\right)$.

\section{Firing patterns}

Prevalence. Table 2 summarizes the prevalence of time-locked responses to the $\mathrm{CS}+$, the CS-, and the US at each of the AMPH doses, segregated by the response type (i.e., excitatory or inhibitory). AMPH doses did not significantly affect the prevalence of neurons responding to the CS+ $\left(\chi_{(3)}^{2}=0.60 ; p=0.90\right), \mathrm{CS}-\left(\chi_{(3)}^{2}=0.47\right.$; $p=0.93)$, or US $\left(\chi_{(3)}^{2}=0.91 ; p=0.82\right)$. When excitatory and inhibitory response types were segregated, there was no relationship between AMPH dose and response type for $\mathrm{CS}+\left(\chi_{(6)}^{2}=3.43 ; p=\right.$ $0.75), \mathrm{CS}-\left(\chi_{(6)}^{2}=3.45 ; p=0.75\right)$, or US $\left(\chi_{(6)}^{2}=0.98 ; p=0.99\right)$ responses, indicating that AMPH doses did not affect the relative distribution of excitatory and inhibitory response types. Table 3 summarizes the prevalence of time-locked responses to the CS+ and the US, segregated by the NAc subregion (i.e., core or shell). A similar proportion of neurons in the core and in the shell showed responses to the US $(z=0.35 ; p=0.73)$, whereas a larger proportion of the core neurons showed responses to the CS+ relative to the shell neurons $(z=2.04$; $p<0.05)$. Nevertheless, no relationship between AMPH dose and NAc subregion was found for either the $\mathrm{CS}+\left(\chi_{(3)}^{2}=0.41 ; p=0.94\right)$ or the US $\left(\chi_{(3)}^{2}=1.23 ; p=0.75\right)$ firing patterns.

Firing rate: excitatory $C S+$ responses. For excitatory CS+ neurons, AMPH increased average firing rate during the $\mathrm{CS}+$ but not during the CS- (Fig. 4A,B). A two-way mixed ANOVA with dose (i.e., 0, $0.25,0.5$, and $1.0 \mathrm{mg} / \mathrm{kg}$ ) and stimulus (i.e., CS+ and $\mathrm{CS}-$ ) as factors showed that there was a significant effect of dose $\left(F_{(3,97)}=6.099 ; p<\right.$ $0.01)$ and a significant dose $\times$ stimulus interaction $\left(F_{(3,97)}=\right.$ 13.368; $p<0.001)$. Post hoc tests showed that average firing during the CS+ was significantly greater at $1.0 \mathrm{mg} / \mathrm{kg} \mathrm{AMPH} \mathrm{com-}$ pared with saline (i.e., $0 \mathrm{mg} / \mathrm{kg}$ AMPH) (Bonferroni, $p<0.001$ ). An additional analysis showed that AMPH did not significantly affect firing rate during the pre-CS $+\left(F_{(3,97)}=2.039 ; p=0.114\right)$ (Fig. $4 A, B$ ).

It was possible that the selective AMPH-induced increase in $\mathrm{CS}+$ firing reflected the similarly selective AMPH-induced increase in trough entry. If this interpretation were correct, one would expect that limiting comparisons of firing to either periods of matched behavior or periods in which trough entry was absent would eliminate the acute drug effect. To test this prediction, we conducted a behavioral clamp control analysis (see Materials and Methods). Briefly, for each excitatory CS + neuron, we calculated firing rate during three CS+ periods, including the following: (1) periods of trough entry (i.e., in), (2) periods of trough exit (i.e., exit), and (3) a non-trough-entry period (i.e., out) (Fig. 4C). A two-way mixed ANOVA with dose and behavior as factors showed that there was a significant effect of behavior on firing rate $\left(F_{(2,194)}=95.796 ; p<0.001\right)$. There was also a significant effect of dose on firing rate $\left(F_{(3,97)}=25.613\right.$; $\left.p<0.001\right)$. However, there was no significant dose $\times$ behavior interaction $\left(F_{(6,194)}=1.641 ; p=0.138\right)$. These findings show that the AMPH-induced increase in excitatory CS+ responses was apparent in the absence of the trough-entry behavior and also when behavior was matched across the different doses of AMPH.

We tested for a different AMPH effect on the excitatory CS+ response of core and shell neurons (Fig. 4D). A two-way ANOVA with subregion (i.e., core vs shell) and dose as factors showed that there was a significant effect of dose $\left(F_{(3,60)}=6.787 ; p<0.001\right)$ and subregion $\left(F_{(1,60)}=4.114 ; p<0.05\right)$, but no interaction between the two factors $\left(F_{(3,60)}=0.079 ; p=0.971\right)$. These results show that the excitatory CS + response was greater in magnitude for core neurons than for shell neurons. Nevertheless, the drug had comparable effects across the two subregions.

Firing rate: inhibitory $\mathrm{CS}+$ responses. Acute AMPH had no significant effect on firing rate of inhibitory $\mathrm{CS}+$ neurons during either the CS+ or the CS- (Fig. 5A,B). A two-way ANOVA showed that there was no significant effect of dose $\left(F_{(3,139)}=\right.$ $0.117 ; p=0.950)$ and no significant dose $\times$ stimulus interaction 
A

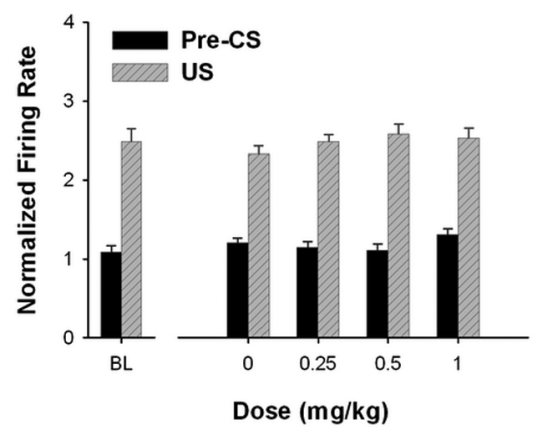

C

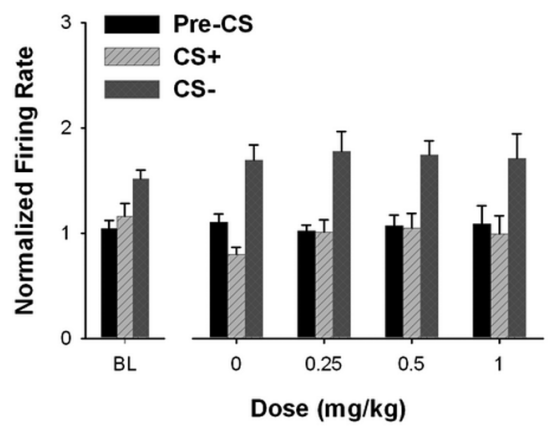

B

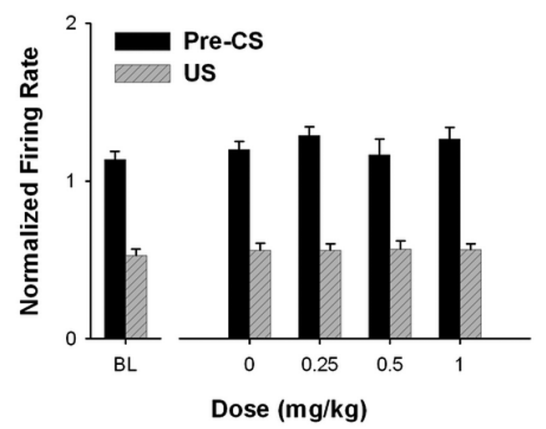

D

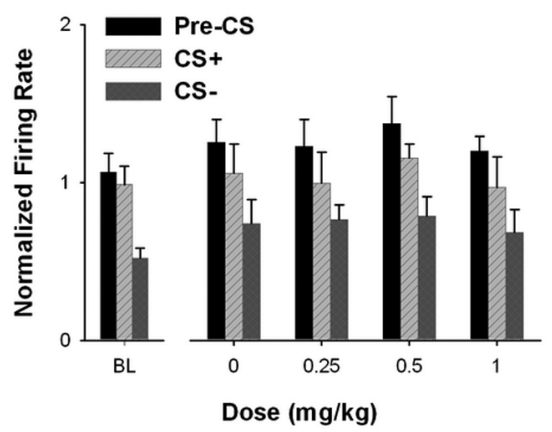

Figure 6. Average US and CS - responses during the acute AMPH phase. $A, B$, For neurons responding to the US, the average normalized firing rate during the pre-CS + and US periods is plotted as a function of AMPH dose. $A$, Neurons excited during the US. $\boldsymbol{B}$, Neurons inhibited during the US. $\boldsymbol{C}, \boldsymbol{D}$, For neurons exhibiting a $C S$ - response, the average normalized firing rate plotted as a function of AMPH dose for the pre-CS+, $C S+$, and $C S$ - periods. $C$, Neurons excited during the $C S-. D$, Neurons inhibited during the $\mathrm{CS}-$. Error bars represent SEM. BL, Baseline.
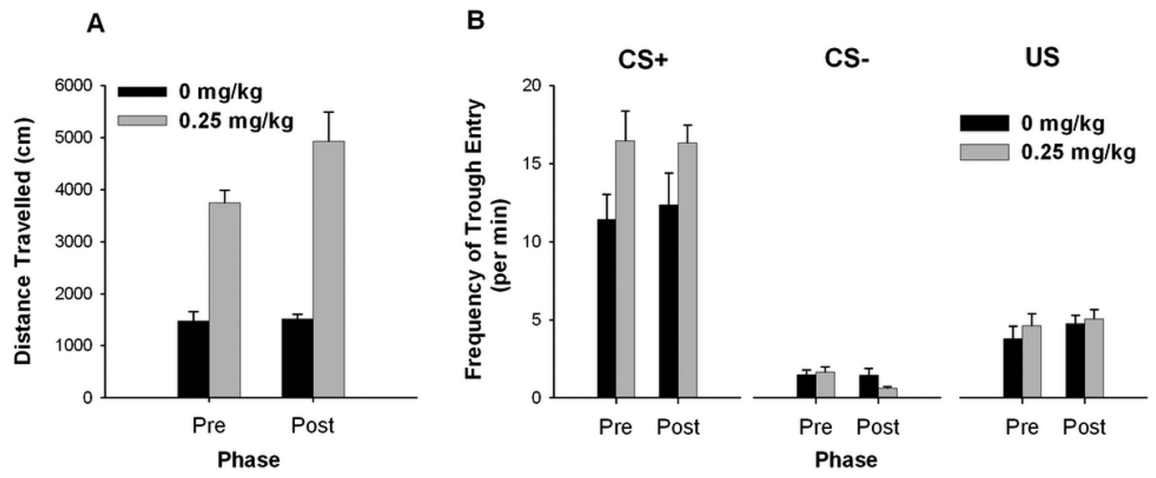

Figure 7. Locomotor activity and the frequency of trough entry before and after the drug-free period. $A$, The locomotor activity score is plotted for both the 0 and the $0.25 \mathrm{mg} / \mathrm{kg} \mathrm{AMPH}$ sessions before and after the drug-free period. $\boldsymbol{B}$, The frequency of trough entry during the $C S+, C S-$, and US periods is plotted for the 0 and $0.25 \mathrm{mg} / \mathrm{kg} \mathrm{AMPH}$ sessions both before and after the drug-free period. In all figures, "Pre" on the $x$-axis indicates sessions before the drug-free period, and "Post" indicates sessions after the drug-free period. Error bars represent SEM.

$\left(F_{(3,139)}=2.536 ; p=0.059\right)$. A separate one-way ANOVA showed that there was also no significant effect of AMPH on firing rate during the pre-CS $+\left(F_{(3,139)}=0.433 ; p=0.730\right.$ ) (Fig. $5 A, B)$.

There was no differential acute AMPH effect on firing rate of inhibitory CS+ neurons when the core and the shell neurons were segregated. A two-way ANOVA with subregion and dose as factors showed that there was no significant effect of subregion $\left(F_{(1,91)}=1.424 ; p=0.236\right)$ and no significant effect of dose $\left(F_{(3,91)}=1.677 ; p=0.177\right)$; moreover, there was no significant subregion $\times$ dose interaction $\left(F_{(3,91)}=0.690 ; p=0.561\right)$.
Firing rate: US responses. For excitatory US neurons, acute AMPH did not significantly affect average firing rate during either the pre-CS+ period or the US period (Fig. 6A). A two-way ANOVA applied to average firing of the excitatory US neurons showed that there was no significant effect of dose $\left(F_{(1,134)}=1.193 ; p=0.315\right)$ and no significant dose $\times$ stimulus interaction $\left(F_{(3,134)}=1.495 ; p=0.219\right)$. A similar analysis applied to average firing of the inhibitory US neurons (Fig. 6B) showed that there was no significant effect of dose $\left(F_{(3,155)}=0.462 ; p=0.709\right)$ and no significant dose $X$ stimulus interaction $\left(F_{(3,155)}\right.$ $=0.205 ; p=0.893$ ).

Firing rate: $C S-$ responses. Acute $\mathrm{AMPH}$ had no significant effect on firing of excitatory CS - neurons during either the CS - or the CS+ (Fig. 6C). A two-way ANOVA showed that there was no significant effect of dose $\left(F_{(3,55)}=0.493 ; p=\right.$ $0.689)$ and no significant dose $\times$ stimulus interaction $\left(F_{(3,55)}=0.854 ; p=0.471\right)$. For inhibitory CS - neurons (Fig. 6D), there was also no significant effect of dose $\left(F_{(3,15)}=1.754 ; p=0.199\right)$ and no dose $X$ stimulus interaction $\left(F_{(3,15)}=0.486 ; p=\right.$ 0.697).

\section{Repeated AMPH \\ Behavior}

Repeated exposure to AMPH followed by a drug-free period (referred to as repeated AMPH) enhanced the effect of acute AMPH on locomotor activity, but did not alter locomotion during saline exposure (Fig. 7A). A two-way repeated-measures ANOVA with dose (i.e., $0 \mathrm{mg} / \mathrm{kg}$ vs 0.25 $\mathrm{mg} / \mathrm{kg}$ AMPH) and phase (i.e., before vs after the drug-free period) showed a dose $\times$ phase interaction $\left(F_{(1,4)}=8.125\right.$; $p<0.05)$, a dose effect $\left(F_{(1,4)}=68.23 ; p<\right.$ $0.001)$, and a phase effect $\left(F_{(1,4)}=1.751\right.$; $p<0.05)$. These findings are consistent with the interpretation that repeated AMPH increased animals' response to the locomotor-activating effect of acute AMPH. This effect has been referred to as "locomotor sensitization" (Robinson and Becker, 1986).

Repeated AMPH did not affect the frequency of trough entry (Fig. 7B). A three-way repeated-measures ANOVA with stimulus, dose, and phase as factors showed that although there was an effect of stimulus $\left(F_{(1,4)}=45.910 ; p<\right.$ $0.001)$, an effect of dose $\left(F_{(1,4)}=7.888 ; p<0.05\right)$, and a dose $\times$ stimulus interaction $\left(F_{(1,4)}=33.00 ; p<0.01\right)$, there was no significant dose $\times$ stimulus $\times$ phase interaction and no dose $X$ phase interaction (both $p>0.05$ ). Similarly, when the frequency of trough entry during the US was examined, there was no significant effect of either phase or dose, and no significant interaction (all $p>0.05$ ). These results show that repeated AMPH did not affect conditioned approach behavior. 


\section{Firing patterns}

Prevalence. There was a trend for the prevalence of event-related firing patterns to increase between the sessions that occurred before and after the drug-free period (Table 4). The increases were not significant when the individual response types were considered separately: $\chi^{2}$ tests with response type (excitatory or inhibitory) and session (i.e., the 0 and 0.25 $\mathrm{mg} / \mathrm{kg}$ AMPH sessions before the drugfree period, and the 0 and $0.25 \mathrm{mg} / \mathrm{kg}$ AMPH sessions after the drug-free period) as factors showed that there was no significant change in prevalence of $\mathrm{CS}+\left(\chi_{(6)}^{2}=\right.$ $4.07 ; p=0.67), \mathrm{CS}-\left(\chi_{(6)}^{2}=3.61 ; p=\right.$ $0.73)$, or US $\left(\chi_{(6)}^{2}=4.11 ; p=0.66\right)$ responses. However, between the AMPH sessions that occurred before and after the drug-free period, there was a significant increase in prevalence of $\mathrm{CS}+$ responsive neurons when excitatory and inhibitory CS+ responses were combined $(z=2.558 ; p<0.05)$.

Firing rate: $C S+$ responses. After the drug-free period, the average firing rate of excitatory $\mathrm{CS}+$ neurons was increased during the CS+ (Fig. $8 A, C)$. A three-way mixed ANOVA with stimulus (i.e., $\mathrm{CS}+$ and $\mathrm{CS}-$ ), dose (i.e., 0 and $0.25 \mathrm{mg} / \mathrm{kg} \mathrm{AMPH}$ ), and phase (i.e., before and after the drug-free period) as factors showed that there was a significant stimulus $\times$ dose $\times$ phase interaction $\left(F_{(1,49)}=4.300 ; p<0.05\right)$ (Fig. $\left.8 C\right)$. Further analyses showed that excitatory $\mathrm{CS}+$ responses during the $0 \mathrm{mg} / \mathrm{kg}$ AMPH session were increased after the drug-free period. A twoway ANOVA showed that there was a significant stimulus $X$ phase interaction $\left(F_{(1,26)}=33.506 ; p<0.001\right)$ when the two 0 $\mathrm{mg} / \mathrm{kg}$ AMPH sessions were compared. In contrast, when the $0.25 \mathrm{mg} / \mathrm{kg}$ AMPH sessions were compared, a two-way ANOVA showed no stimulus $\times$ phase interaction $\left(F_{(1,23)}=1.426 ; p=\right.$ $0.245)$, indicating that repeated AMPH failed to further potentiate the acute effect of $0.25 \mathrm{mg} / \mathrm{kg} \mathrm{AMPH}$ on the CS+ firing rate.

Repeated AMPH did not affect the average firing rate of inhibitory CS+ neurons (Fig. $8 B$ and $8 D$ ). For this subset of neurons, a three-way ANOVA showed no stimulus $\times$ dose $\times$ phase interaction $\left(F_{(1,52)}=0.050 ; p=0.824\right)$.

Firing rate: US responses. Repeated AMPH did not affect firing rate of US responsive neurons. In neurons exhibiting excitatory US responses (Fig. 9A), a three-way ANOVA with stimulus (i.e., pre-CS+ and US), dose, and phase as factors showed that there was no stimulus $\times$ dose $\times$ phase interaction $\left(F_{(1,55)}=0.591 ; p=\right.$ $0.445)$, no dose $\times$ phase interaction $\left(F_{(1,55)}=2.721 ; p=0.105\right)$, and no effect of either dose $\left(F_{(1,55)}=0.791 ; p=0.378\right)$, or phase $\left(F_{(1,55)}=0.228 ; p=0.635\right)$, indicating that repeated AMPH did not affect firing rate during either the US or the pre-CS + period. Similarly, in neurons exhibiting inhibitory US responses (Fig. $9 B$ ), a three-way ANOVA showed that there was no significant stimulus $\times$ dose $\times$ phase $\left(F_{(1,86)}=1.301 ; p=0.257\right)$ or dose $\times$ phase $\left(F_{(1,86)}=0.282 ; p=0.597\right)$ interaction. There was also no significant effect of either dose $\left(F_{(1,86)}=3.809 ; p=0.054\right)$ or phase $\left(F_{(1,86)}=1.297 ; p=0.258\right)$.

Firing rate: $C S-$ responses. Repeated AMPH did not affect the excitatory CS - responses (Fig. 9C). A three-way ANOVA with stimulus (i.e., CS - and CS +), dose, and phase as factors showed no significant stimulus $\times$ dose $\times$ phase interaction $\left(F_{(1,30)}=\right.$ $0.452 ; p=0.507)$, no significant dose $\times$ phase interaction $\left(F_{(1,30)}\right.$ $=0.001 ; p=0.975)$, and no effect of either dose $\left(F_{(1,30)}=0.147\right.$; $p=0.704)$ or phase $\left(F_{(1,30)}=0.564 ; p=0.459\right)$. Very few neurons showing inhibitory $\mathrm{CS}-$ responses were found. Thus, the average firing rate of the neurons was shown in Figure 9D, but no statistical examination was performed.

\section{Summary of the major findings of the acute and repeated AMPH phases}

Acute AMPH increased pavlovian conditioned approach. AMPH concomitantly increased the amplitude of excitatory neuronal responses to the CS+. There was no acute AMPH effect on neuronal responses to the US, nor was there an AMPH effect on CSneuronal responses. Excitatory CS + responses were stronger in the core than in the shell, whereas the core and the shell neurons were similarly affected by acute AMPH. Although repeated AMPH induced locomotor sensitization, it did not affect conditioned approach behavior. Nevertheless, repeated AMPH increased the prevalence of neuronal responses during the $\mathrm{CS}+$ and also increased the amplitude of excitatory CS+ neuronal responses.

\section{Discussion \\ Acute AMPH}

Behavior

Previous studies have shown that acute AMPH enhances the conditioned reinforcing and energizing effects of CS + stimuli on instrumental behavior (Robbins, 1978; Taylor and Robbins, 1984; Wyvell and Berridge, 2000). In the present study, acute AMPH similarly strengthened the impact of CS + stimuli on pavlovian conditioned approach behavior. Tindell et al. (2005) did not observe a similar AMPH effect on conditioned approach. However, there were numerous conditioning [e.g., an additional CS + in the study by Tindell et al. (2005)] and pharmacological parameters (e.g., AMPH dose) that differed between the present study and that of Tindell et al. (2005). These observations suggest that the acute AMPH effect on conditioned approach is parameter sensitive.

\section{CS + neuronal responses}

The observation that AMPH affected CS + but not CS - neuronal responses is subject to multiple potential functional interpretations. A selective effect on the CS + response could reflect a drug effect on NAc responses to sensory (i.e., physical) characteristics of the CS + . However, this interpretation can be excluded given that the light and white noise stimuli used as the CS + and CSwere counterbalanced across animals. Another potential inter- 
A

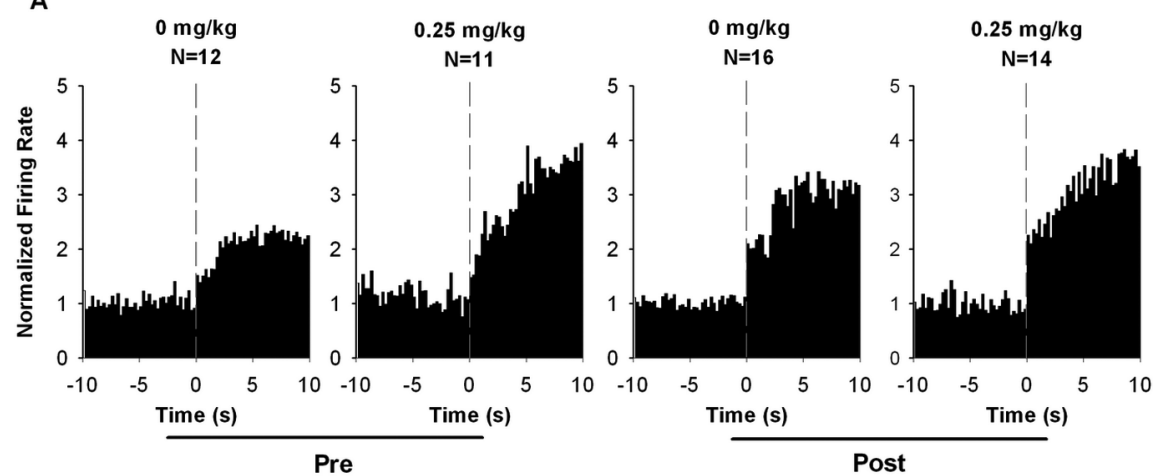

B

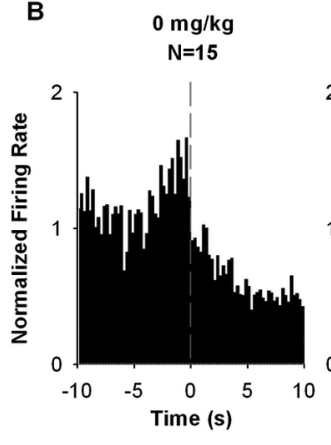

$0.25 \mathrm{mg} / \mathrm{kg}$

$\mathrm{N}=10$
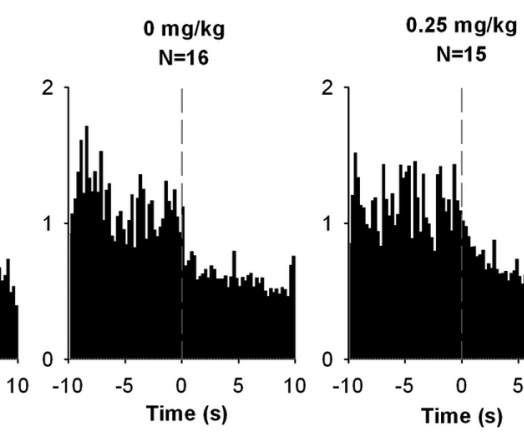

$\mathrm{N}=15$

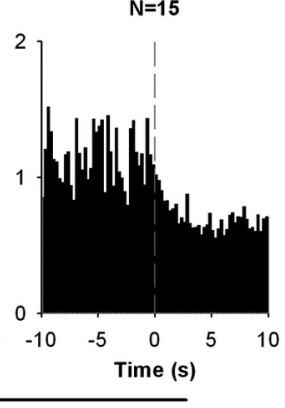

Pre

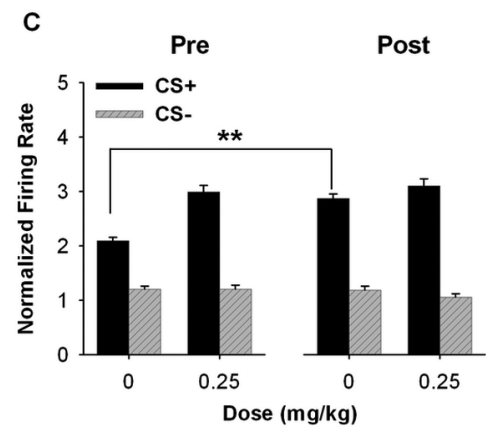

Post

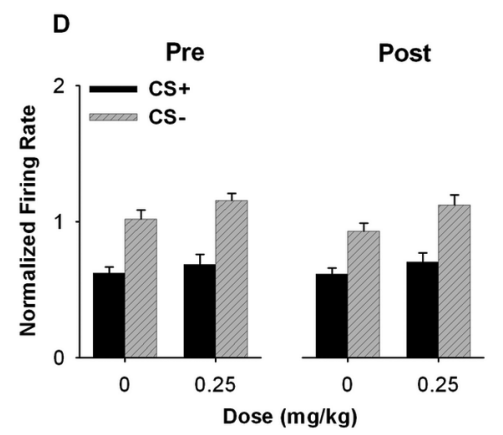

Figure 8. Average $C S+$ responses before and after the drug-free period. $A, B$, Population perievent histograms showing the average responses of neurons exhibiting either an excitatory $(\boldsymbol{A})$ or inhibitory $(\boldsymbol{B})$ response to the $C S+$. In each histogram, the average normalized firing rate is plotted as a function of $0.25 \mathrm{~s}$ time bins for the $10 \mathrm{~s}$ pre- $\mathrm{CS}+$ and the $10 \mathrm{~s} C \mathrm{~S}+$ period. The vertical dashed line at time 0 represents the onset of the $C S+. C, D$, For neurons exhibiting $C S+$ responses, the average normalized firing rate during the $C S+$ and $C S$ - periods is plotted for the 0 and $0.25 \mathrm{mg} / \mathrm{kg} \mathrm{AMPH} \mathrm{sessions} \mathrm{both} \mathrm{before} \mathrm{and} \mathrm{after} \mathrm{the} \mathrm{drug-free}$ period. $\boldsymbol{C}$, Neurons excited during the $C S+. D$, Neurons inhibited during the $C S+$. Error bars represent SEM. ${ }^{* *} p<0.01$.

pretation of the AMPH effect is that it reflected the drug-induced increase in trough entry during the CS + . However, this interpretation can be excluded given the results of the behavioral clamp analysis. Based on these findings, the AMPH effect on CS + firing most likely reflected a drug effect on NAc neuronal responses to one or more conditioned characteristics of the CS+ (e.g., the predictive relationship between the CS+ and the US).

Although the acute AMPH effect on CS+ firing was dissociable from the trough entry behavior per se, the drug effect on $\mathrm{CS}+$ firing could have nevertheless contributed to the AMPHinduced increase in the frequency of the conditioned approach behavior. This interpretation is supported by the observation that AMPH actions in the NAc are sufficient for amplification of the energizing and conditioned reinforcing effects of CS + stimuli on conditioned behavior (Robbins, 1978; Taylor and Robbins, 1984; Wyvell and Berridge, 2000). Moreover, the NAc is necessary for acquisition and expression of pavlovian conditioned approach
(Parkinson et al., 1999; Cardinal et al., 2002). Given these observations, AMPHinduced changes in NAc CS + firing could have contributed to the selective increase in conditioned approach during CS+ presentations.

Previous studies have shown that the NAc core is required for the expression of CS + effects, whereas the shell is necessary for the acute AMPH-induced enhancement of CS + effects (Parkinson et al., 1999). In the present study, CS + responses were greater in prevalence and magnitude in the core than in the shell, although the AMPH effect on CS+ responses was comparable across the two subregions. The difference in strength of $\mathrm{CS}+$ responses may be relevant to understanding the differential involvement of the NAc core and shell in pavlovian conditioned stimulus effects.

The mechanisms that mediated the effects of systemically administered AMPH on NAc neuronal activity in the present study could include drug actions in NAc afferents (Tindell et al., 2005; Homayoun and Moghaddam, 2006), the NAc itself, or both. In considering potential intra-NAc mechanisms, multiple lines of evidence support a possible role for changes in DA transmission, including the following: (1) DA transmission within the NAc is involved in regulating pavlovian conditioned approach (Di Ciano et al., 2001; Parkinson et al., 2002; Eyny and Horvitz, 2003; Dalley et al., 2005); (2) presentations of CS + stimuli elevate NAc DA (Roitman et al., 2004); (3) NAc DA is necessary for AMPH effects on the reinforcing properties of CS + stimuli (Taylor and Robbins, 1986); (4) DA and direct DA agonists can mimic the effects of AMPH on NAc firing (Kiyatkin and Rebec, 1996; Nicola et al., 1996; Nicola and Malenka, 1997); and (5) DA antagonists can block AMPH-induced modulation of NAc firing (Nicola et al., 1996; Kiyatkin and Rebec, 1997).

US neuronal responses

Acute AMPH did not affect US neuronal responses. The lack of drug effects on US responses is consistent with evidence that DA transmission within the NAc is not critically involved in mediating consummatory behaviors, including feeding (Bakshi and Kelley, 1991; Baldo et al., 2002; Cannon and Palmiter, 2003; Cheng et al., 2003; Hanlon et al., 2004).

\section{Comparison to other electrophysiological studies}

Both bath application of AMPH in vitro and iontophoretic AMPH administration in freely moving animals decrease activity in NAc neurons (Nicola et al., 1996; Kiyatkin and Rebec, 1997; Li and Kauer, 2004). In contrast, systemic AMPH administration in behaving animals has more heterogeneous effects (Rebec, 1987; Haracz et al., 1993; Kessal et al., 2005). The present study showed 
that systemic AMPH administration in behaving animals can enhance particular excitatory task-related firing patterns, while leaving others unaffected. The different acute AMPH effects observed among the various studies could reflect betweenexperiment differences in either (1) NAc AMPH concentration or (2) route of drug administration (local vs systemic). The different AMPH effects also could reflect a DA-mediated, afferent-specific or activityspecific AMPH effect [cf. Nicola et al. (2000), O’Donnell (2003), and West et al. (2003)].

\section{Repeated AMPH \\ Behavior}

Repeated exposure to psychostimulants, particularly if followed by an extended drug-free period, can induce locomotor sensitization (Robinson and Becker, 1986) and enhance the energizing and reinforcing effects of CS+ stimuli in drug-free animals (Taylor and Horger, 1999; Wyvell and Berridge, 2001). In the present study, repeated AMPH increased the locomotor-activating effects of AMPH but had no effect on conditioned approach behavior. Tindell et al. (2005) made a similar observation. Other studies of conditioned approach have shown that a history of AMPH before any conditioning history enhances the rate of conditioned approach during early (drug-free) conditioning sessions. However, the same treatment has no effect on expression of the behavior in later sessions, once behavior is asymptotic (Harmer and Phillips, 1998; Taylor and Jentsch, 2001). Thus, multiple studies have failed to observe an effect of repeated AMPH on expression of well conditioned approach behavior.

In considering potential explanations for the absence of a repeated-AMPH effect on well established conditioned approach, one can formulate a number of hypotheses, some of which include the following. First, it is possible that other behaviors enhanced by repeated AMPH interfere with expression of conditioned approach. Second, neuroadaptations induced by repeated AMPH are not wholly consistent with those necessary for an upregulation of previously acquired conditioned approach. Third, it is interesting to note that in all cases in which an effect of repeated AMPH was observed, measurement of conditioned behavior occurred in situations that were novel to animals (i.e., during acquisition of a new conditioned behavior or during exposure to a previously conditioned CS + in a novel behavioral setting). This contrasts with studies of AMPH effects on well established conditioned approach behavior. A possible effect of novelty is supported by evidence that novelty impacts the firing rate of DA neurons to conditioned stimuli (Ljungberg et al., 1992; Schultz et al., 1993), as well as the role of NAc DA in goal-directed behavior (Smith-Roe and Kelley, 2000).

Accumbal firing patterns

Repeated AMPH was associated with an increase in the prevalence of CS + responsive neurons and an increase in the am-
B
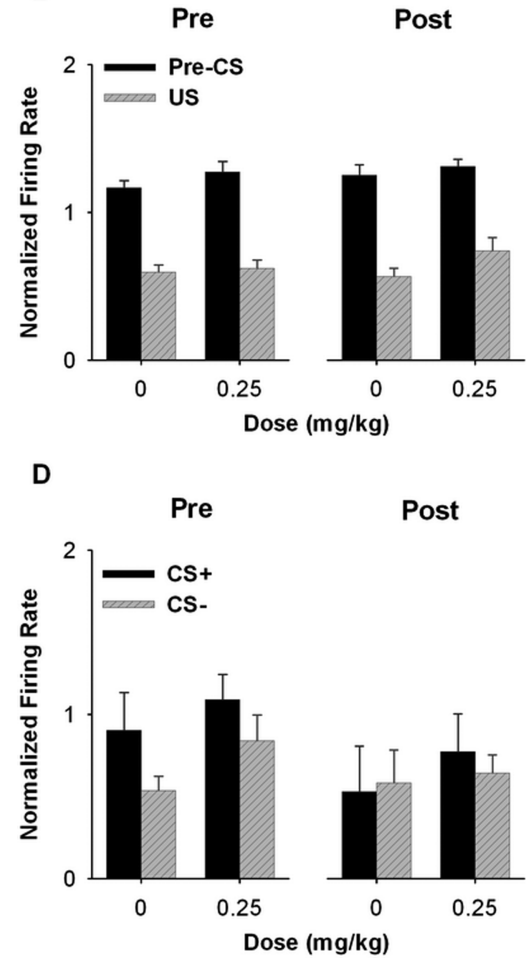


\section{Conclusions}

It is hypothesized that acute and repeated AMPH-induced enhancements of CS + effects on behavior are mediated by an amplification of NAc neuronal responses to CS+ stimuli. The present data support this hypothesis. Further evaluation of the hypothesis will require additional characterization of the effects of AMPH on conditioned approach, and tests of whether the present neuronal findings generalize to AMPH effects on the energizing and reinforcing properties of pavlovian conditioned stimuli.

\section{References}

Bakshi VP, Kelley AE (1991) Dopaminergic regulation of feeding behavior II. Differential effects of amphetamine microinfusion into three striatal subregions. Psychobiology 19:233-242.

Baldo BA, Sadeghian K, Basso AM, Kelley AE (2002) Effects of selective dopamine D1 or D2 receptor blockade within nucleus accumbens subregions on ingestive behavior and associated motor activity. Behav Brain Res 137:165-177.

Bonhomme N, Cador M, Stinus L, Le Moal M, Spampinato U (1995) Short and long-term changes in dopamine and serotonin receptor binding sites in amphetamine-sensitized rats: a quantitative autoradiographic study. Brain Res 675:215-223.

Brady AM, Glick SD, O'Donnell P (2003) Changes in electrophysiological properties of nucleus accumbens neurons depend on the extent of behavioral sensitization to chronic methamphetamine. Ann N Y Acad Sci 1003:358-363.

Brebner K, Wong TP, Liu L, Liu Y, Campsall P, Gray S, Phelps L, Phillips AG, Wang YT (2005) Nucleus accumbens long-term depression and the expression of behavioral sensitization. Science 310:1340-1343.

Cannon CM, Palmiter RD (2003) Reward without dopamine. J Neurosci 23:10827-10831.

Cardinal RN, Parkinson JA, Lachenal G, Halkerston KM, Rudarakanchana N, Hall J, Morrison CH, Howes SR, Robbins TW, Everitt BJ (2002) Effects of selective excitotoxic lesions of the nucleus accumbens core, anterior cingulate cortex, and central nucleus of the amygdala on autoshaping performance in rats. Behav Neurosci 116:553-567.

Cheng JJ, de Bruin JPC, Feenstra MGP (2003) Dopamine efflux in nucleus accumbens shell and core in response to appetitive classical conditioning. Eur J Neurosci 18:1306-1314.

Dalley JW, Lääne K, Theobald DE, Armstrong HC, Corlett PR, Chudasama Y, Robbins TW (2005) Time-limited modulation of appetitive pavlovian memory by D1 and NMDA receptors in the nucleus accumbens. Proc Natl Acad Sci U S A 102:6189-6294.

Day JJ, Carelli RM (2007) The nucleus accumbens and pavlovian reward learning. Neuroscientist 13:148-159.

Di Ciano P, Cardinal RN, Cowell RA, Little SJ, Everitt BJ (2001) Differential involvement of NMDA, AMPA/kainate, and dopamine receptors in the nucleus accumbens core in the acquisition and performance of pavlovian approach behavior. J Neurosci 21:9471-9477.

Everitt BJ, Dickinson A, Robbins TW (2001) The neuropsychological basis of addictive behavior. Brain Res Brain Res Rev 36:129-138.

Eyny YS, Horvitz JC (2003) Opposing roles of $\mathrm{D}_{1}$ and $\mathrm{D}_{2}$ receptors in appetitive conditioning. J Neurosci 23:1584-1587.

Giorgetti M, Hotsenpiller G, Ward P, Teppen T, Wolf ME (2001) Amphetamine-induced plasticity of AMPA receptors in the ventral tegmental area: effects on extracellular levels of dopamine and glutamate in freely moving rats. J Neurosci 21:6362-6369.

Groenewegen HJ, Berendse HW, Haber SN (1993) Organization of the output of the ventral striatopallidal system in the rat: ventral pallidal efferents. Neuroscience 57:113-142.

Hanlon EC, Baldo BA, Sadeghian K, Kelley AE (2004) Increases in food intake or food-seeking behavior induced by GABAergic, opioid, or dopaminergic stimulation of the nucleus accumbens: is it hunger? Psychopharmacology 172:241-247.

Haracz JL, Tschanz JT, Wang Z, White IM, Rebec GV (1993) Striatal singleunit responses to amphetamine and neuroleptics in freely moving rats. Neurosci Biobehav Rev 17:1-12.

Harmer CJ, Phillips GD (1998) Enhanced appetitive conditioning following repeated pretreatment with d-amphetamine. Behav Pharmacol 9:299-308.
Hollander JA, Carelli RM (2005) Abstinence from cocaine self-administration heightens neural encoding of goal-directed behaviors in the accumbens. Neuropsychopharmacology 30:1464-1474.

Hollander JA, Carelli RM (2007) Cocaine-associated stimuli increase cocaine seeking and activate accumbens core neurons after abstinence. J Neurosci 27:3535-3539.

Homayoun H, Moghaddam B (2006) Progression of cellular adaptations in medial prefrontal and orbitofrontal cortex in response to repeated amphetamine. J Neurosci 26:8025-8039.

Kessal K, Chessel A, Spennato G, Garcia R (2005) Ketamine and amphetamine both enhance synaptic transmission in the amygdala-nucleus accumbens pathway but with different time-courses. Synapse 57:61-65.

Kiyatkin EA, Rebec GV (1996) Dopaminergic modulation of glutamateinduced excitations of neurons in the neostriatum and nucleus accumbens of awake, unrestrained rats. J Neurophysiol 75:142-153.

Kiyatkin EA, Rebec GV (1997) Iontophoresis of amphetamine in the neostriatum and nucleus accumbens of awake, unrestrained rats. Brain Res 771:14-24.

Li Y, Kauer JA (2004) Repeated exposure to amphetamine disrupts dopaminergic modulation of excitatory synaptic plasticity and neurotransmission in nucleus accumbens. Synapse 51:1-10.

Ljungberg T, Apicella P, Schultz W (1992) Responses of monkey dopamine neurons during learning of behavioral reactions. J Neurophysiol 67:145-163.

Lu W, Chen H, Xue C-J, Wolf ME (1997) Repeated amphetamine administration alters the expression of mRNA for AMPA receptor subunits in rat nucleus accumbens and prefrontal cortex. Synapse 26:269-280.

Lu W, Monteggia LM, Wolf ME (1999) Withdrawal from repeated amphetamine administration reduces NMDAR1 expression in the rat substantia nigra, nucleus accumbens and medial prefrontal cortex. Eur J Neurosci 11:3167-3177.

Nicola SM, Malenka RC (1997) Dopamine depresses excitatory and inhibitory synaptic transmission by distinct mechanisms in the nucleus accumbens. J Neurosci 17:5697-5710.

Nicola SM, Kombian SB, Malenka RC (1996) Psychostimulants depress excitatory synaptic transmission in the nucleus accumbens via presynaptic $\mathrm{D}_{1}$-like dopamine receptors. J Neurosci 16:1591-1604.

Nicola SM, Surmeier J, Malenka RC (2000) Dopaminergic modulation of neuronal excitability in the striatum and nucleus accumbens. Annu Rev Neurosci 23:185-215.

O'Donnell P (2003) Dopamine gating of forebrain neural ensembles. Eur J Neurosci 17:429-435.

Parkinson JA, Olmstead MC, Burns LH, Robbins TW, Everitt BJ (1999) Dissociation in effects of lesions of the nucleus accumbens core and shell on appetitive pavlovian approach behavior and the potentiation of conditioned reinforcement and locomotor activity by D-amphetamine. J Neurosci 19:2401-2411.

Parkinson JA, Dalley JW, Cardinal RN, Bamford A, Fehnert B, Lachenal G, Rudarakanchana N, Halkerston KM, Robbins TW, Everitt BJ (2002) Nucleus accumbens dopamine depletion impairs both acquisition and performance of appetitive pavlovian approach behaviour: implications for mesoaccumbens dopamine function. Behav Brain Res 137:149-163.

Paxinos G, Watson C (2005) The rat brain in stereotaxic coordinates. San Diego: Elsevier Academic.

Peoples LL (2003) Application of chronic extracellular recording to studies of drug self-administration. In: Methods in drug abuse research: cellular and circuit level analyses (Waterhouse BD, ed), pp 161-211. Boca Raton, FL: CRC.

Peoples LL, Kravitz AV, Lynch KG, Cavanaugh DJ (2007a) Accumbal neurons that are activated during cocaine self-administration are spared from inhibitory effects of repeated cocaine self-administration. Neuropsychopharmacology 32:1141-1158.

Peoples LL, Kravitz AV, Guillem K (2007b) The role of accumbal hypoactivity in cocaine addiction. Scientific WorldJournal 7:22-45.

Rebec GV (1987) Electrophysiological pharmacology of amphetamine. Monogr Neural Sci 13:1-33.

Robbins TW (1978) The acquisition of responding with conditioned reinforcement: effects of pipradrol, methylphenidate, d-amphetamine, and nomifensine. Psychopharmacology 58:79-87.

Robinson TE, Becker JB (1986) Enduring changes in brain and behavior produced by chronic amphetamine administration: a review and evaluation of animal models of amphetamine psychosis. Brain Res 396:157-198. 
Robinson TE, Kolb B (1997) Persistent structural modifications in nucleus accumbens and prefrontal cortex neurons produced by previous experience with amphetamine. J Neurosci 17:8491-8497.

Robinson TE, Kolb B (1999) Alterations in the morphology of dendrites and dendritic spines in the nucleus accumbens and prefrontal cortex following repeated treatment with amphetamine or cocaine. Eur J Neurosci 11:1598-1604.

Robinson TE, Jurson PA, Bennett JA, Bentgen KM (1988) Persistent sensitization of dopamine neurotransmission in ventral striatum (nucleus accumbens) produced by prior experience with $(+)$-amphetamine: a microdialysis study in freely moving rats. Brain Res 462:211-222.

Roitman MF, Stuber GD, Phillips PE, Wightman RM, Carelli RM (2004) Dopamine operates as a subsecond modulator of food seeking. J Neurosci 24:1265-1271.

Roseboom PH, Hewlett GH, Gnegy ME (1990) Repeated amphetamine administration alters the interaction between D1-stimulated adenylyl cyclase activity and calmodulin in rat striatum. J Pharmacol Exp Ther 255:197-203.

Schultz W, Apicella P, Ljungberg T (1993) Responses of monkey dopamine neurons to reward and conditioned stimuli during successive steps of learning a delayed response task. J Neurosci 13:900-913.

Smith-Roe SL, Kelley AE (2000) Coincident activation of NMDA and dopamine $D_{1}$ receptors within the nucleus accumbens core is required for appetitive instrumental learning. J Neurosci 20:7737-7742.

Taylor JR, Horger BA (1999) Enhanced responding for conditioned reward produced by intra-accumbens amphetamine is potentiated after cocaine sensitization. Psychopharmacology 142:31-40.

Taylor JR, Jentsch JD (2001) Repeated intermittent administration of psychomotor stimulant drugs alters the acquisition of pavlovian approach behavior in rats: differential effects of cocaine, d-amphetamine and 3,4methylenedioxymethamphetamine ("ecstasy"). Biol Psychiatry 50:137-143.

Taylor JR, Robbins TW (1984) Enhanced behavioural control by conditioned reinforcers following microinjections of $\mathrm{d}$-amphetamine into the nucleus accumbens. Psychopharmacology 84:405-412.
Taylor JR, Robbins TW (1986) 6-Hydroxydopamine lesions of the nucleus accumbens, but not of the caudate nucleus, attenuate enhanced responding with reward-related stimuli produced by intra-accumbens d-amphetamine. Psychopharmacology 90:390-397.

Tindell AJ, Berridge KC, Zhang J, Peciña S, Aldridge JW (2005) Ventral pallidal neurons code incentive motivation: amplification by mesolimbic sensitization and amphetamine. Eur J Neurosci 22:2617-2634.

Wan X, Peoples LL (2006) Firing patterns of accumbal neurons during a pavlovian-conditioned approach task. J Neurophysiol 96:652-660.

West AR, Floresco SB, Charara A, Rosenkranz JA, Grace AA (2003) Electrophysiological interactions between striatal glutamatergic and dopaminergic systems. Ann N Y Acad Sci 1003:53-74.

Winstanley CA, Eagle DM, Robbins TW (2006) Behavioral models of impulsivity in relation to ADHD: translation between clinical and preclinical studies. Clin Psychol Rev 26:379-395.

Wolf ME, White FJ, Nassar R, Brooderson RJ, Khansa MR (1993) Differential development of autoreceptor subsensitivity and enhanced dopamine release during amphetamine sensitization. J Pharmacol Exp Ther 264:249-255.

Wolf ME, White FJ, Hu XT (1994) MK-801 prevents alterations in the mesoaccumbens dopamine system associated with behavioral sensitization to amphetamine. J Neurosci 14:1735-1745.

Wyvell CL, Berridge KC (2000) Intra-accumbens amphetamine increases the conditioned incentive salience of sucrose reward: enhancement of reward "wanting" without enhanced "liking" or response reinforcement. J Neurosci 20:8122-8130.

Wyvell CL, Berridge KC (2001) Incentive sensitization by previous amphetamine exposure: increased cue-triggered "wanting" for sucrose reward. J Neurosci 21:7831-7840.

Zahm DS (2000) An integrative neuroanatomical perspective on some subcortical substrates of adaptive responding with emphasis on the nucleus accumbens. Neurosci Biobehav Rev 24:85-105. 